\title{
The Effects of Multipropped Deep Excavation-Induced Ground Movements on Adjacent High-Rise Building Founded on Piled Raft in Sand
}

\author{
Mukhtiar Ali Soomro $\mathbb{D D}^{1}{ }^{1}$ Naeem Mangi, ${ }^{1}$ Wen-Chieh Cheng, ${ }^{2}$ and Dildar Ali Mangnejo ${ }^{3}$ \\ ${ }^{1}$ Department of Civil Engineering, Quaid-e-Awam University of Engineering, Science \& Technology, Nawabshah, Sindh, Pakistan \\ ${ }^{2}$ School of Civil Engineering, Xi'an University of Architecture and Technology, Xi'an 710055, China \\ ${ }^{3}$ Department of Civil Engineering, Mehran University of Engineering \& Technology, Shaheed Zulfiqar Ali Bhutto Campus, \\ Khairpur Mirs, Pakistan
}

Correspondence should be addressed to Mukhtiar Ali Soomro; eng.soomro@gmail.com

Received 6 July 2020; Revised 9 September 2020; Accepted 15 September 2020; Published 24 October 2020

Academic Editor: Jinyang Xu

Copyright (C) 2020 Mukhtiar Ali Soomro et al. This is an open access article distributed under the Creative Commons Attribution License, which permits unrestricted use, distribution, and reproduction in any medium, provided the original work is properly cited.

\begin{abstract}
In this paper, a three-dimensional numerical parametric study was conducted to predict the deformation mechanism of a 20 storey building sitting on a $(4 \times 4)$ piled raft to an adjacent $25 \mathrm{~m}$ deep basement excavation. The influences of different excavation depths were investigated. An advanced hypoplastic sand model (which is capable of taking small-strain stiffness into account) was adopted to capture soil behaviour. The computed results revealed that excavation adjacent to a building resting on the piled raft caused significant settlement, differential settlement, lateral deflection, and interstorey drift in the building. With settlement due to working load (i.e., $4.8 d_{p} \%$ ), the total settlements of the building $\left(7.8 d_{p} \%\right)$ exceed the maximum allowable foundation settlement (i.e., $50 \mathrm{~mm}$ ). In addition, substantial bending moment, shear forces, and changes in axial load distribution along pile length were induced. The findings from this study revealed that the building and pile responses are significantly influenced by the excavation depth.
\end{abstract}

\section{Introduction}

Underground space has become increasingly important in relieving the shortage of lands in megacities with rapid economic development and dramatic increase of population [1]. Deep basements for underground facilities such as subway stations are usually excavated near existing buildings and bridges. Basement excavation-induced stress relief and ground movements inevitably cause additional deformation and stress on adjacent pile foundations [2, 3]. It is highly likely that excavation-induced ground movement and stress relief may lead to severe damage and might result in collapse of structure. Thus, it is a major concern for designers and engineers to evaluate adverse effects of basement excavation on buildings. To ensure the safety and serviceability of existing pile foundations, several researchers have studied this complex problem by means of different approaches. Rocha [4] systematically described scale modeling for problems in soil mechanics in a $1 \mathrm{~g}$ gravitation field. Moncarz and Krawinkler [5] considered that if an adequate model correctly scales the primary features of the problem, the scaling relations between the prototype and model are not significantly affected. In the previous research study, Sawwaf and Nazir [6] analyzed the results of laboratory model tests on the influence of deep excavation-induced lateral soil movements on the behaviour of a model strip footing adjacent to the excavation and discussed the variation of the footing measured vertical settlements with different parameters. Fang et al. [7] conducted physical model tests of highway tunnel construction and examined the stability of the surrounding rocks regarding different caved zone-tunnel distances and dip angles of the coal seam. 
Yang et al. [8] investigated the mechanical behaviour of a typical jointed rock block located adjacent to an underground excavation by comparing the failure modes of the numerical simulations with the corresponding experimental physical jointed block test results. Shahin et al. [9-11] studied about the influence of existing building load on the deformation and earth pressure of the ground in shallow tunnelling by two-dimensional model tests and numerical analysis. Kusui et al. [12] conducted a large number of scaled-down tunnel experiments to investigate the response of unsupported walls to an increased stress field. Xu et al. [13] carried out a series of three-dimensional shaking table tests to investigate the mechanism and effect of seismic measures of the mountain tunnel using a scaled model based on a real tunnel. Furthermore, the centrifuge test was often used to study the effect of excavation construction, and Liyanapathirana and Nishanthan [14] and Zhang et al. [15] analyzed the excavation-induced pile behaviour using the finite element method and the centrifuge test. In terms of influence parameters of excavation construction, Yashiro et al. [16] conducted parameter analysis focusing on the overburden and the stiffness coefficient of the ground by anecdotal surveying and numerical analysis. Boone et al. [17] provided a modified approach for estimating potential damage and compared to case histories using construction data from a large braced excavation. Hsiao et al. [18, 19] considered the calculated settlement as the load in the context of reliability analysis and proposed a simplified model for evaluating the damage potential of a building adjacent to a braced excavation. Long [20] summarized the general trends and patterns based on some 300 case histories of wall and ground movements due to deep excavations worldwide. Among those numerical studies, however, responses of the framed building to excavation were reported in a limited number of studies. Most of these aforementioned research studies only examined the tunnelling effects on buildings founded on shallow footings [21-24]. Therefore, there is a gap of systematic research on the responses of a high-rise building subjected to live load and resting on the piled raft to advancement of adjacent excavation. The paper aims to understand the responses of a 20-storey building to ground movement due to excavation-induced stress relief. To achieve this, three-dimensional finite element analysis was conducted. The building deformation (i.e., differential settlement, deflection, and interstorey drift) and piled raft (i.e., induced bending moment and shear forces in the piles) were presented and discussed.

\section{Development of Three-Dimensional Finite Element Model}

2.1. General. With the prime objective of investigating the excavation building interaction, three-dimensional finite element analysis was adopted in this study. An excavation was carried out in the close proximity of a 20-storey high rising building which is resting on a $(4 \times 4)$ piled raft foundation in sand. Figure 1(a) illustrates the general setup of the 20-storey building founded on a piled raft and a basement. In practice, the final excavation depth of the basement commonly varied from 12 to $26 \mathrm{~m}$, and the thickness of the retaining wall varied from 0.3 to $1.0 \mathrm{~m}$ $[1,6,25]$. To simulate an actual construction in practice, the basement with a final excavation depth of $25 \mathrm{~m}$ (staged excavation) and a wall thickness of $0.3 \mathrm{~m}$ was simulated in this study. The depth of first and eighth (i.e., final) stages was $2 \mathrm{~m}$ and the depth of each of remaining stages (i.e., second to seven) was taken as $3 \mathrm{~m}$. The ratio of wall penetration depth to excavation depth is typically $0.5-2$ in engineering practice $[1,6,26]$, and thus a value of 0.6 is adopted in this study. The retaining wall was supported by eight levels of props with vertical and horizontal spacing of $3.0 \mathrm{~m}$ and $5 \mathrm{~m}$, respectively. The first level of props was installed at $2.0 \mathrm{~m}$ below the ground surface. The props are modeled as soft with axial rigidity of $81 \times 10^{3} \mathrm{kNm}$ [21-26]. A $60 \mathrm{~m}$ high, $15 \mathrm{~m}$ wide 20storey, concrete building with three spans in each direction was selected in the study. The building was founded on a square raft, which was $15 \mathrm{~m}$ wide and $1.5 \mathrm{~m}$ thick supported by a group of piles in a $4 \times 4$ configuration with a centre-to-centre distance of $3.75 \mathrm{~m}$ (see Figure 1(b)). The diameter $\left(d_{p}\right)$ and length $\left(L_{p}\right)$ of each pile were $1 \mathrm{~m}$ and $20 \mathrm{~m}$, respectively. The clear distance between the closest pile and the diaphragm wall was $2.0 \mathrm{~m}\left(2 d_{p}\right)$. Since the prime objective of this parametric study is to assess the impact of excavation on the 20-storey building under dead and live loads, the live load of $5 \mathrm{kPa}$ [27] was adopted in this study. With this adopted piled raft system, the numerical prediction showed that settlement of the building due to dead and live load was $45.2 \mathrm{~mm}\left(4.52 \% d_{p}\right)$ which is within the limit of the allowable foundation settlement of $50 \mathrm{~mm}$ given by Skempton and Macdonald [28] and O’Brien [29].

2.2. Features of the Building. Figure 2 illustrates the building and its sections of structural components. The structural sections were adopted from Rasouli and Fatahi [30]. They designed the sections by conducting a routine design procedure by conducting analysis and design using SAP2000 [31] based on AS3600 [32], AS1170.1 [27], and AS1170.4 [33]. The details of all sections are summarized in Table 1. The specific compressive strength $\left(f_{c}^{\prime}\right)$ and mass density of the concrete members in the building were considered to be $32 \mathrm{MPa}$ and $2400 \mathrm{~kg} / \mathrm{m}^{3}$, respectively, and the modulus of elasticity of concrete was estimated to be equal to $30.1 \mathrm{GPa}$.

2.3. Characteristics of the Numerical Model. Figure 3 shows the finite element mesh developed in Abaqus software. The size of the mesh numerical run was taken as $50 \mathrm{~m} \times 50 \mathrm{~m}$ $\times 60 \mathrm{~m}$. The different structural components of the building (i.e., columns and slabs) were modeled by using two-node linear beam elements (B31) and four-node shell elements (S4). The mechanical behaviour of structural elements of the building was modeled using an elastic-perfectly plastic constitutive model to capture any possible inelastic behaviour of the structural elements; these structural elements could behave elastically until they reached yielding stress that was equal to the compressive strength of concrete (i.e., 


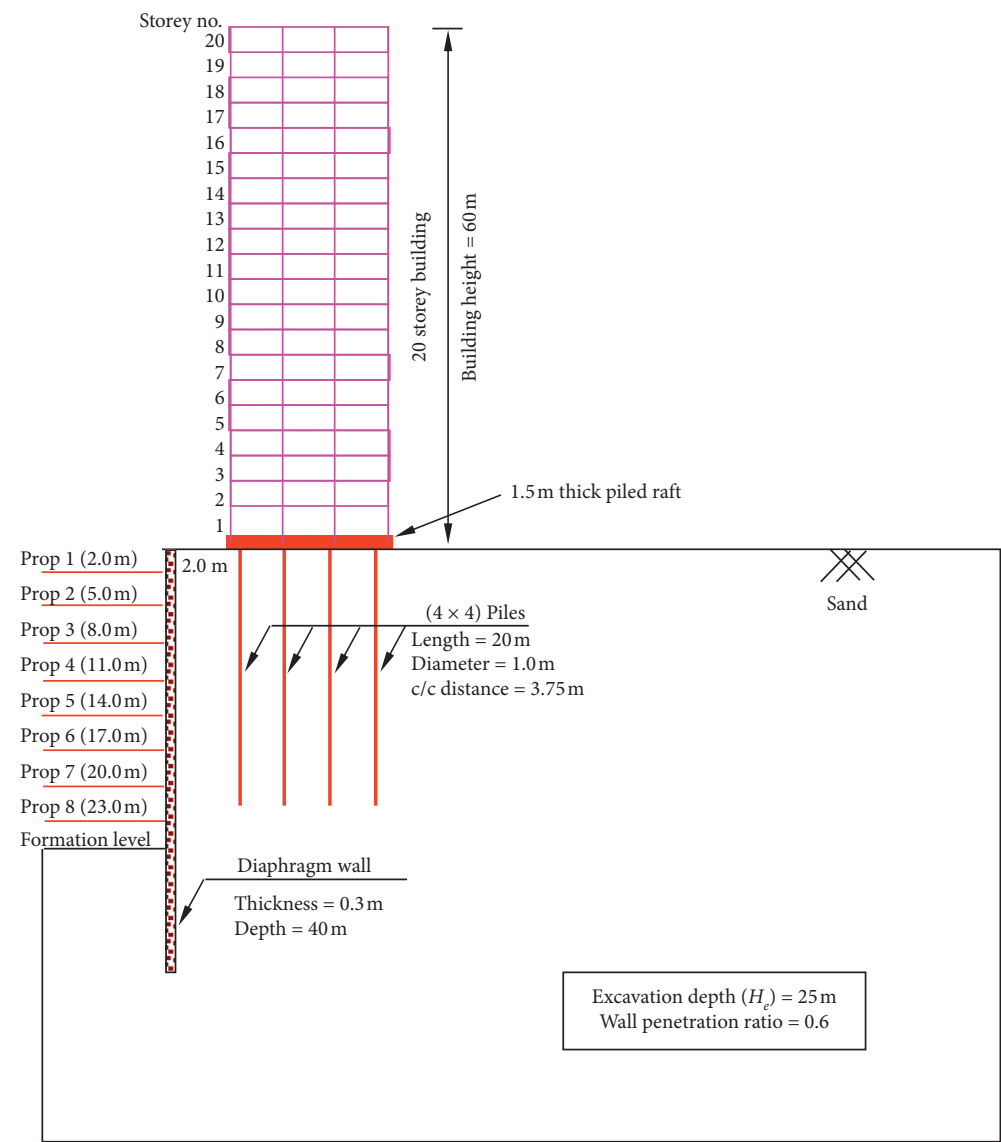

(a)

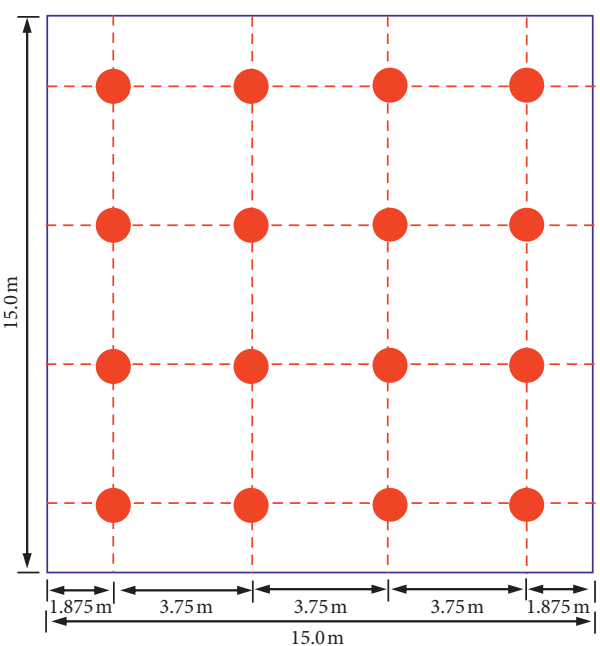

(b)

FIgURe 1: (a) General setup of building, piled raft, and excavation. (b) Piles arrangement in the raft.

$f_{c}^{\prime}=32 \mathrm{MPa}$ ) taken from the study of Shing and Tanabe [25]. Eight-noded hexahedral brick elements are used to model the soil, the pile, and the diaphragm wall, while two-noded truss elements are adopted to model the props.

Since the stress-strain relationship of soils is highly nonlinear even at very small strain and the stiffness of soil depends on the recent stress or strain history of the soil [34-38], an advanced hypoplastic model was used to simulate the behaviour of sand in this study. The basic hypoplastic soil model requires eight material parameters to describe the nonlinear behaviour of sand $\left(\phi_{c}^{\prime}, h_{s}, n, e_{d 0}, e_{c 0}, e_{i 0}, \alpha\right.$, and $\left.\beta\right)$. Parameter $\phi_{c}^{\prime}$ is the soil frictional angle at a critical state. Parameters $h_{s}$ and $n$ are used to describe the shape of limiting void ratio lines. Parameters $e_{d 0}, e_{c 0}$, and $e_{i 0}$ are reference void ratios of isotropic normal compression line, critical state line, and minimum void ratio line, respectively. Effects of soil relative density on peak frictional angle and shear stiffness are characterized by parameters of $\alpha$ and $\beta$. To consider the small-strain stiffness and stress path-dependent soil behaviour, the concept of intergranular strain is incorporated into the basic model [39], which includes additional five parameters $\left(m_{R}, m_{T}, R, \beta_{r}\right.$, and $\left.\chi\right)$. By using the concept of intergranular strain, the modified hypoplastic sand model has the ability to capture effects of shear strain and stress path on soil stiffness [40]. These five parameters were obtained by fitting the stiffness degradation curves of Toyoura sand (see Figure 4) obtained from the stress- path triaxial tests carried out by $\mathrm{Ng}$ et al. [41]. Figure 4 shows the measured secant modulus degradation curves corresponding to four varying recent stress histories (i.e., $\theta=0,90$, -90 , and $180^{\circ}$ ), based on the GDS and CKC triaxial automated testing systems. It can be seen that the measured results in the tests for $u=180^{\circ}$ by the GDS and CKC triaxial testing systems had fairly similar trends. Quantitatively, the percentage differences between the secant modulus measured by the two triaxial testing systems were less than $18 \%$. The model parameters were taken from a study by Shi et al. [21]. They calibrated and validated all the parameters of the hypoplastic sand model against their centrifuge test results (which was performed to simulate excavation in sand). These parameters are summarized in Table 2. The lateral coefficient of earth pressure $\left(K_{0}\right)$ is estimated by the empirical equation $\left(1-\sin \varphi^{\prime}\right)$ proposed by Jáky [42], where $\varphi^{\prime}$ is internal frictional of soil at the critical state. Since the internal friction angle of Toyoura sand at the critical state is $31^{\circ}$, the $\mathrm{K}_{0}$ value is estimated as 0.5 .

2.4. Soil Structure Interactions and Boundary Conditions. While modeling excavation-pile-soil problem, one of the important aspects of modeling soil structure interaction (SSI) is to establish interaction between pile and surrounding soil. To incorporate the interactions between pile- 


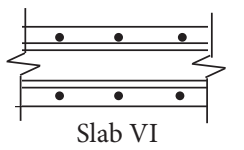

(0.25 $\mathrm{m}$ thick)

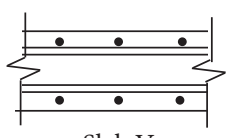

Slab V

(0.25 m thick)

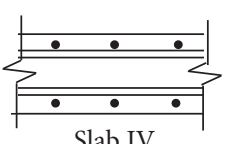

Slab IV

( $0.25 \mathrm{~m}$ thick)

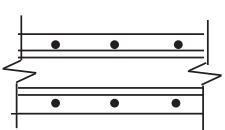

Slab III

(0.25 m thick)

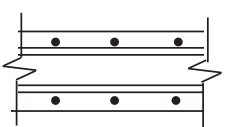

Slab II

(0.25 m thick)

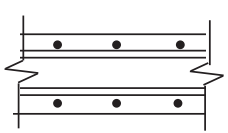

Slab I

(0.25 $\mathrm{m}$ thick)

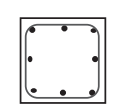

Column VI

$\left(0.50 \times 0.50 \mathrm{~m}^{2}\right)$

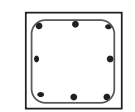

Column V

$\left(0.55 \times 0.55 \mathrm{~m}^{2}\right)$

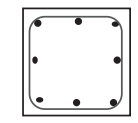

Column IV $\left(0.60 \times 0.60 \mathrm{~m}^{2}\right)$

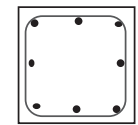

Column III $\left(0.65 \times 0.65 \mathrm{~m}^{2}\right)$

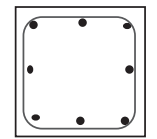

Column II $\left(0.70 \times 0.70 \mathrm{~m}^{2}\right)$

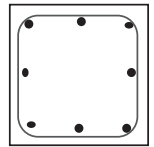

Column I $\left(0.75 \times 0.75 \mathrm{~m}^{2}\right)$

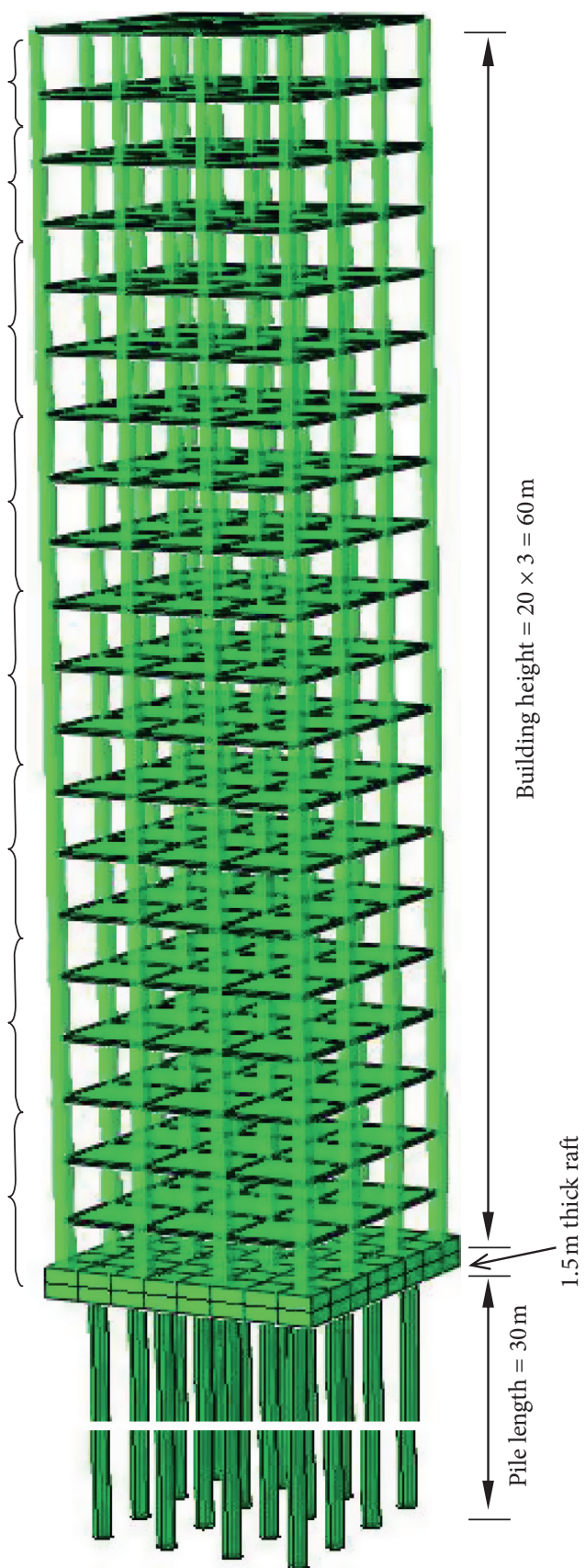

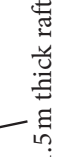

Figure 2: Designed sections of columns and slabs.

TABLE 1: Summary of numerical simulations [30].

\begin{tabular}{lccccccc}
\hline Section type & Column I & Column II & Column III & Column IV & Column V & Column VI & Slab \\
\hline Dimension $(\mathrm{m})$ & $0.75 \times 0.75$ & $0.70 \times 0.70$ & $0.65 \times 0.65$ & $0.6 \times 0.6$ & $0.55 \times 0.55$ & $0.50 \times 0.50$ & $13.5 \times 13.5 \times 0.25$ \\
Distribution level & $1-3$ & $4-7$ & $8-11$ & $12-15$ & $16-18$ & $19-20$ & All levels \\
Cross-sectional area, A $\left(\mathrm{m}^{2}\right)$ & 0.5625 & 0.49 & 0.4225 & 0.36 & 0.3025 & 0.25 & $0.25(1 \mathrm{~m}$ width) \\
Flexural rigidity, EI $\left(\mathrm{GPa} . \mathrm{m}^{4}\right)$ & 0.794 & 0.602 & 0.448 & 0.325 & 0.230 & 0.157 & 0.039 \\
\hline
\end{tabular}

soil and raft-soil, the surface-to-surface contact technique provided in the Abaqus software package was used [43]. In this approach, two surfaces in contact were assigned as the master and slave surfaces. The penalty approach was used for tangential contact, and the normal behaviour is modeled as hard contact with no normal relative displacement between the pile and surrounding soil. The interface was modeled by the Coulomb friction law, in which the interface friction 


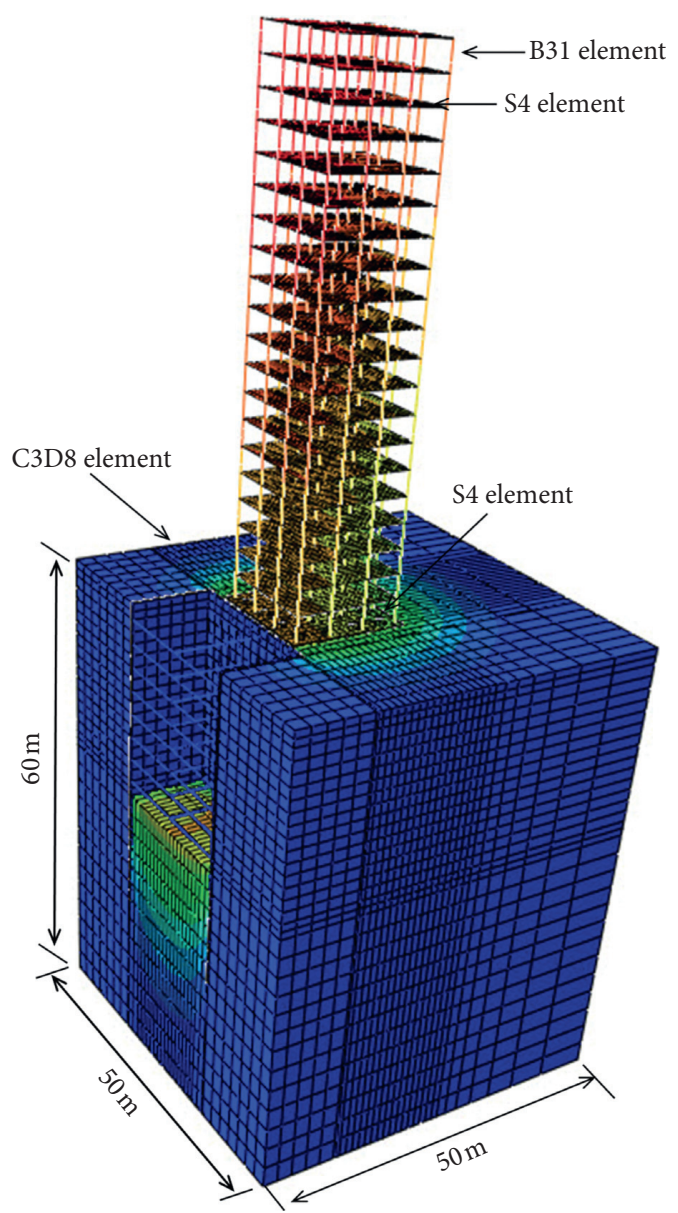

Figure 3: 3D finite element mesh (showing the model of building, raft, and ground).

coefficient $(\mu)$ and limiting displacement $\left(\gamma_{\text {lim }}\right)$ are required as input parameters. A limiting shear displacement of $5 \mathrm{~mm}$ was assumed to achieve full mobilization of the interface friction equal to $\mu \times p^{\prime}$, where $p^{\prime}$ is the normal effective stress between two contact surfaces, and a typical value 0.35 of $\mu$ for a bored pile was used in all analyses [35]. Roller and pin supports were applied to the vertical sides and the base of the mesh, respectively. Therefore, movements normal to the vertical boundaries and in all directions of the base were restrained. The excavation process will be simulated by deactivating soil elements inside the excavation zone. In the meantime, the truss elements representing the props will be activated.

The concrete pile, the diaphragm wall, and the props were assumed to be linear elastic with Young's modulus of $35 \mathrm{GPa}$ and Poisson's ratio of 0.25 . The unit weight of the concrete was assumed to be $24 \mathrm{kN} / \mathrm{m}^{3}$. The parameters for the piles and the diaphragm wall are summarized in Table 3.

2.5. Numerical Simulation. The numerical simulations of all the three cases were carried out in the following steps.

(a) Step 1: initial geostatic stresses are generated in the mesh by applying gravity load and the coefficient of lateral earth pressure of 0.5 .

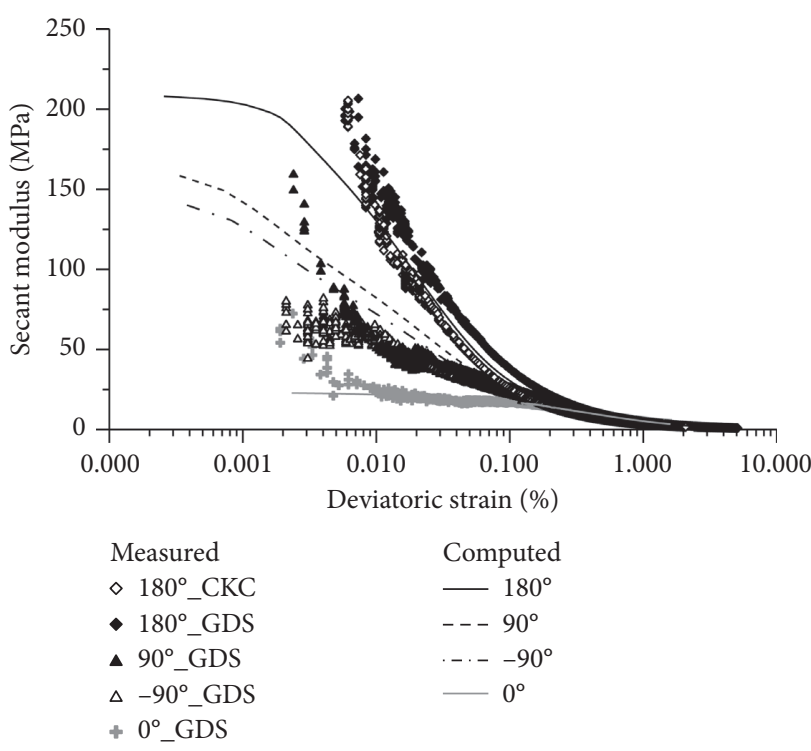

FIgURE 4: Measured and computed degradation curves of Toyoura sand subjected to varying recent stress histories [41].

(b) Step 2: the piles are constructed, and then a raft is placed on the top of the pile group and soil deposit.

(c) Step 3: the 20-storey building is constructed on the top of the piled raft. A live load of $5 \mathrm{kPa}$ is applied on the floor slab of each storey.

(d) Step 4: the brick elements representing the diaphragm wall are activated.

(e) Step 5: staged multipropped excavation is simulated as described in Section 2.1. After excavating to $2 \mathrm{~m}$ depth, the first level of props is installed at $2 \mathrm{~m}$ below the ground surface.

(f) Step 6: repeat step 6 to excavate the next stages and install props until the last stage of excavation (i.e., $\left.H_{e}=25 \mathrm{~m}\right)$ is completed.

\subsection{Validation of Numerical Modeling against Centrifuge Test} Result. Before conducting any numerical parametric study, the measured ground surface settlement in centrifuge test results reported by Shi et al. [21] was used to validate the soil constitutive model and model parameters adopted in the finite element analyses. Figure 5 shows the comparison between measured and computed ground surface settlement trough developed on completion of the excavation. Both the ground surface settlement $(S)$ and the distance behind the wall in the transverse direction are normalised by final excavation depth $\left(H_{e}\right)$. It can be observed from the figure that the measured and computed settlement troughs show reasonable agreement. In this study, multipropped basement excavation is simulated. Thus, concave-shaped profile of ground settlement behind the wall is observed, as expected. The measured maximum soil settlement is observed at a distance of $0.375 \mathrm{H}_{e}$, while the induced settlement is negligible when the distance from the wall exceeds $2.5 H_{e}$. When the normalised distance from the basement is $0.375 H_{e}$, the 
TABLE 2: Hypoplastic model parameters of sand adopted in this study.

\begin{tabular}{lc}
\hline Description & Parameter \\
\hline Effective angle of shearing resistance at critical state, $\phi^{\prime}$ & $31^{\circ}$ \\
Coefficient of at-rest earth pressure, $K_{o}$ & 0.5 \\
Hardness of Granulates, $h_{s}$ & $2.6 \mathrm{GPa}$ \\
Exponent $n$ & 0.27 \\
Minimum void ratio at zero pressure, $e_{d o}$ & 0.61 \\
Maximum void ratio at zero pressure, $e_{i o}$ & 1.10 \\
Critical void ratio at zero pressure, $e_{c o}$ & 0.98 \\
Exponent $\alpha$ & 0.14 \\
Exponent $\beta$ & 6 \\
Parameter controlling initial shear modulus upon $180^{\circ}$ strain path reversal, $m_{R}$ & 6 \\
Parameter controlling initial shear modulus upon $90^{\circ}$ strain path reversal, $m_{T}$ & \\
Size of elastic range, $R$ & \\
Parameter controlling degradation rate of stiffness with strain, $\beta_{r}$ & $2 \times 10^{-5}$ \\
Parameter controlling degradation rate of stiffness with strain, $\chi$ & 0.1 \\
\hline
\end{tabular}

TABLE 3: Concrete parameters adopted in finite element analysis.

\begin{tabular}{lc}
\hline Description & Parameter \\
\hline Young's modulus, $E$ & $35 \mathrm{GPa}$ \\
Poisson's ratio, $v$ & 0.3 \\
Density, $\rho$ & $2400 \mathrm{~kg} / \mathrm{m}^{3}$ \\
\hline
\end{tabular}

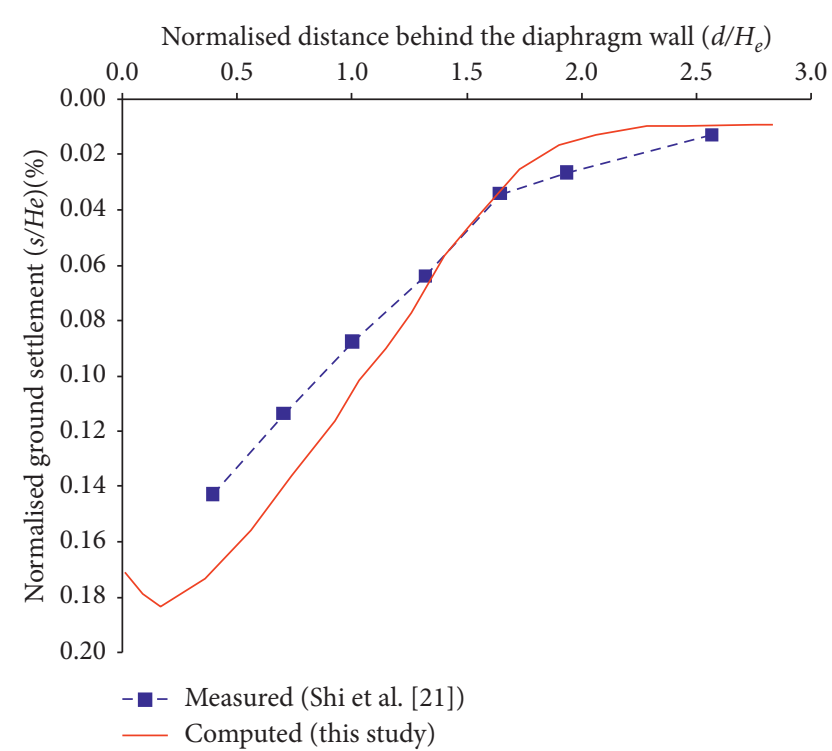

FIgURE 5: Comparison of the measured and computed ground surface settlement.

computed ground surface settlement at the end of basement excavation is $0.17 \% H_{e}$, which is $18 \%$ larger than the measured one $\left(0.143 \% H_{e}\right)$.

\section{Interpretation of Computed Results}

3.1. Settlement of Piled Raft. Settlement of the piled raft at its centre $\left(S_{p}\right)$ induced due to different excavation stages is plotted in Figure 6. The piled settlement is normalised by the pile diameter. Excavation depths are indicated by $h$ which is normalised by final excavation depth $\left(H_{e}\right)$. It can be seen from the figure that bilinear increment in $S_{p}$ was observed with increasing excavation depth. $S_{p}$ increased linearly when excavation depth reached $h / H_{e}=0.68$; however, the rate of induced settlement further increased until final excavation depth $\left(h / H_{e}=1.00\right)$. This was because of degradation of sand stiffness due to excavation-induced stress and the plastic strain generated surrounding the piles due to excavationinduced stress release. Since the initial excavation stages $\left(0<h / H_{e}<0.68\right)$ are adjacent to the pile shaft, the shafts of the piles were affected by excavation-induced plastic strain. However, the toes of the piles were resting on the intact (from plastic strain) stiffer layer, whereas toes of the piles were severely influenced by the plastic strain as excavation stages passed beyond the pile toes $\left(h / H_{e}>1.00\right)$. Consequently, the piled raft experienced larger settlement due to excavation stages beyond $h / H_{e}>0.68$ as compared to the initial excavation stages. On completion of the excavation, the piled raft settlement was $30 \mathrm{~mm}\left(3.0 d_{p} \%\right)$. With settlement due to working load (i.e., $4.8 d_{p} \%$ ), the total settlements of the building $\left(7.8 d_{p} \%\right)$ exceed the maximum allowable foundation settlement (i.e., $50 \mathrm{~mm}$ ) according to Skempton and Macdonald [28] and O'Brien [29]. Hence, the numerical prediction implies that the serviceability limit state of a building founded on the pile can be affected when excavation is carried out adjacent to the building.

3.2. Differential Settlement of Piled Raft. In addition to the discussion of piled raft settlement in the previous section, differential settlement induced in the building is an important parameter to investigate. During the excavation of nearby piled raft foundation, as expected, piles closest to the excavation are subjected to larger ground movement and stress release than those which are farthest from the excavation. As a result, differential settlement is induced in the piles. Figure 7 shows settlements of the piled raft induced at various positions along the centreline of the raft (see inset in the figure) at different excavation stages (i.e., $h / H_{e}=0.08$, $0.32,0.56,0.80$, and 1.00 ). The settlement before excavation is added in the figure for reference. It can be seen that after completion of the building construction (before excavation), the settlement occurred in the building was uniform through 


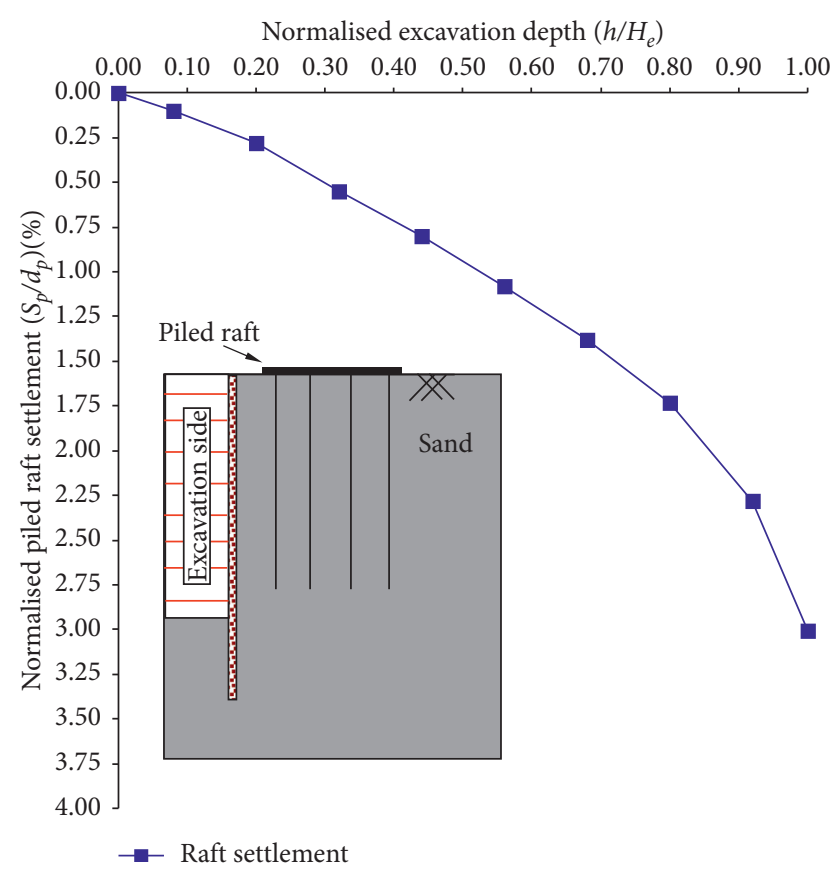

Figure 6: Piled raft settlement during excavation.

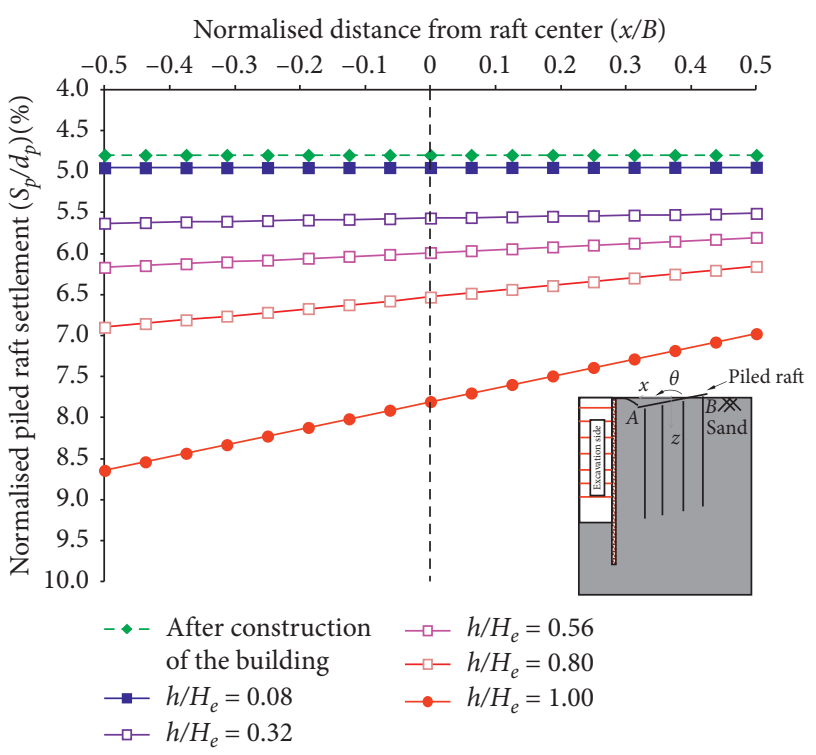

Figure 7: Evolution of differential settlement in the raft.

the centreline of the raft. However, as excavation was carried out, the raft corner closest to the diaphragm wall settled larger than that furthest from the wall. After the completion of the first excavation stage (i.e., $h / H_{e}=0.08$ ), negligible differential settlement was predicted. However, as excavation depth increases, the differential settlement increases. This observation is attributed to excavation-induced stress release which is larger and smaller around the pile closest to and farthest from the excavation. The induced differential settlement caused the building permanent interstorey drifts (discussed in Section 3.3). The differential settlement in the raft of 3.6, 7.4, and $16.7 \mathrm{~mm}$ was induced on completion of excavation stages $h / H_{e}=0.56,0.80$, and 1.00 , respectively.

3.3. Flooring Lateral Displacement and Interstorey Drifts. The numerical predictions in the previous section showed that the excavation resulted in differential settlement of the raft. This led to displace the 20-storey building laterally towards the excavation. Figure 8(a) illustrates the induced lateral deflection of the building along each storey at different excavation stages (i.e., $h / H_{e}=0.08,0.32,0.56,0.80$, and 1.00). It can be seen from the figure that lateral deflection increased with the height of the building. Negligible lateral deflection was computed after the first excavation stage (i.e., $h / H_{e}=0.08$ ). However, as the excavation continues, the substantial lateral deflection was induced in the building. This observation is consistent with induced settlement in the piled raft. The maximum lateral deflection occurred at the top of the building (the roof level of $20^{\text {th }}$ storey). The general trend of the lateral deflection profile is consistent with differential settlement. Since interstorey drift may induce distress in structural component of the building, it is necessary to predict the drift induced in the building due to excavation at different stages. Figure 8(b) illustrates interstorey drift of the building during excavation. The interstorey drift of the building can be defined as ratio of difference of deflections at two storeys to storey height. It is noted that interstorey drift shows similar trend as that of lateral deflection. The drift of $0.024 \%, 0.05 \%$, and $0.11 \%$ was predicted on completion of excavation stages $h / H_{e}=0.56$, 0.80 , and 1.00 , respectively.

3.4. Computed Ground Deformation Mechanism and Deviatoric Strain. Figure 9 shows computed incremental displacement vectors due to excavation. In addition, computed incremental shear strain of the excavation-induced stress release is also superimposed in the figure. It can be observed that soil on the retained side moved towards the excavation, whereas the soil underneath the excavation heaved upwards due to vertical stress relief inside the exaction zone. Furthermore, it can be seen that excavationinduced ground movement is mainly bounded by a wedge at an angle of $45^{\circ}$ drawn from the wall toe. In addition to ground movement, significant shear strain (up to $1.0 \%$ ) is also developed extending nearly at $45^{\circ}$ from the wall toe. A similar pattern and magnitude of excavation-induced shear strain were calculated from the measured centrifuge test in sand [21]. This indicates that the finite element analysis results are appropriate to analyze the excavation pile interaction problem.

It can be seen that all the piles are located at the zone of ground movement. Moreover, the piles closest to the diaphragm wall are subjected to larger ground movement as compared to farthest piles. This caused the differential settlement (see Figure 7) in the piled raft. Because the entire pile length is affected by the ground movement due to excavation-induced stress release, shaft resistance decreased. To maintain equilibrium, the pile had to settle which resulted in increment in end bearing (explained in Section 3.6). On 


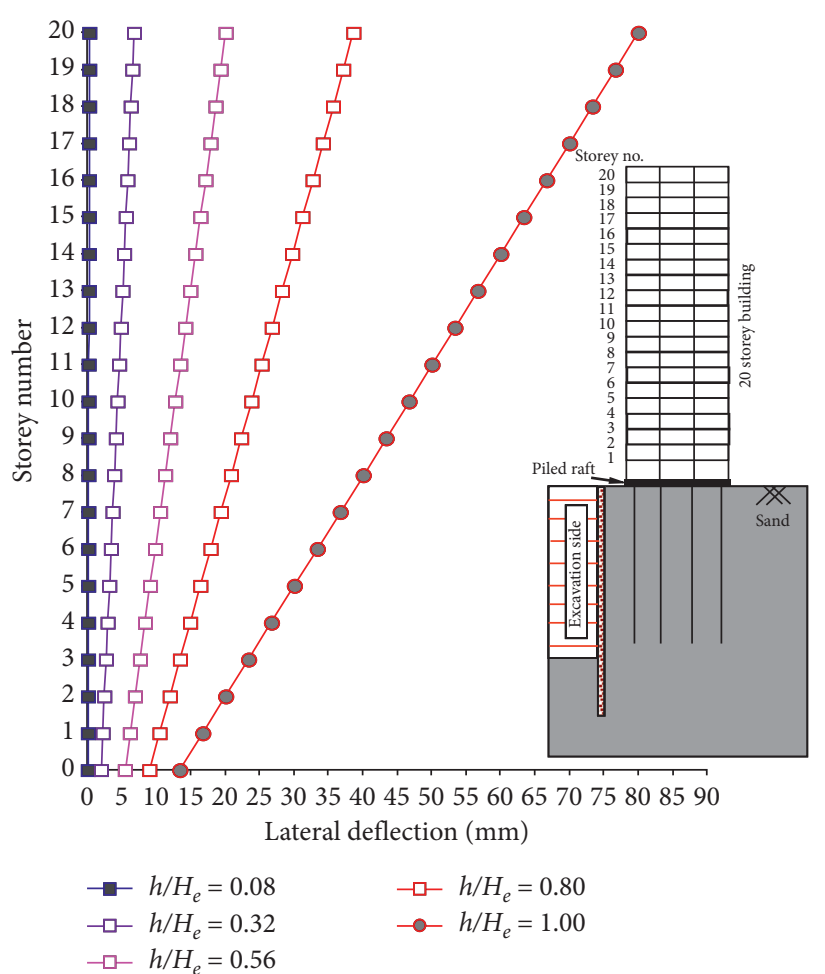

(a)

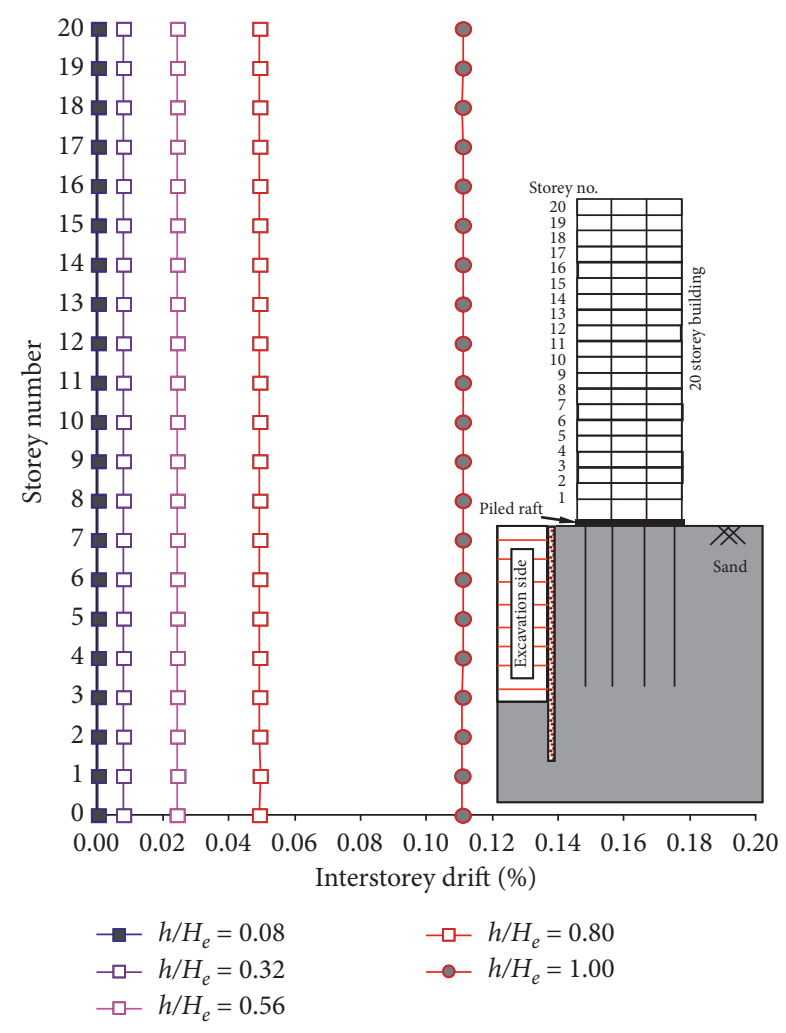

(b)

FIgURE 8: Lateral deflection and interstorey drift of the building on completion of excavation.

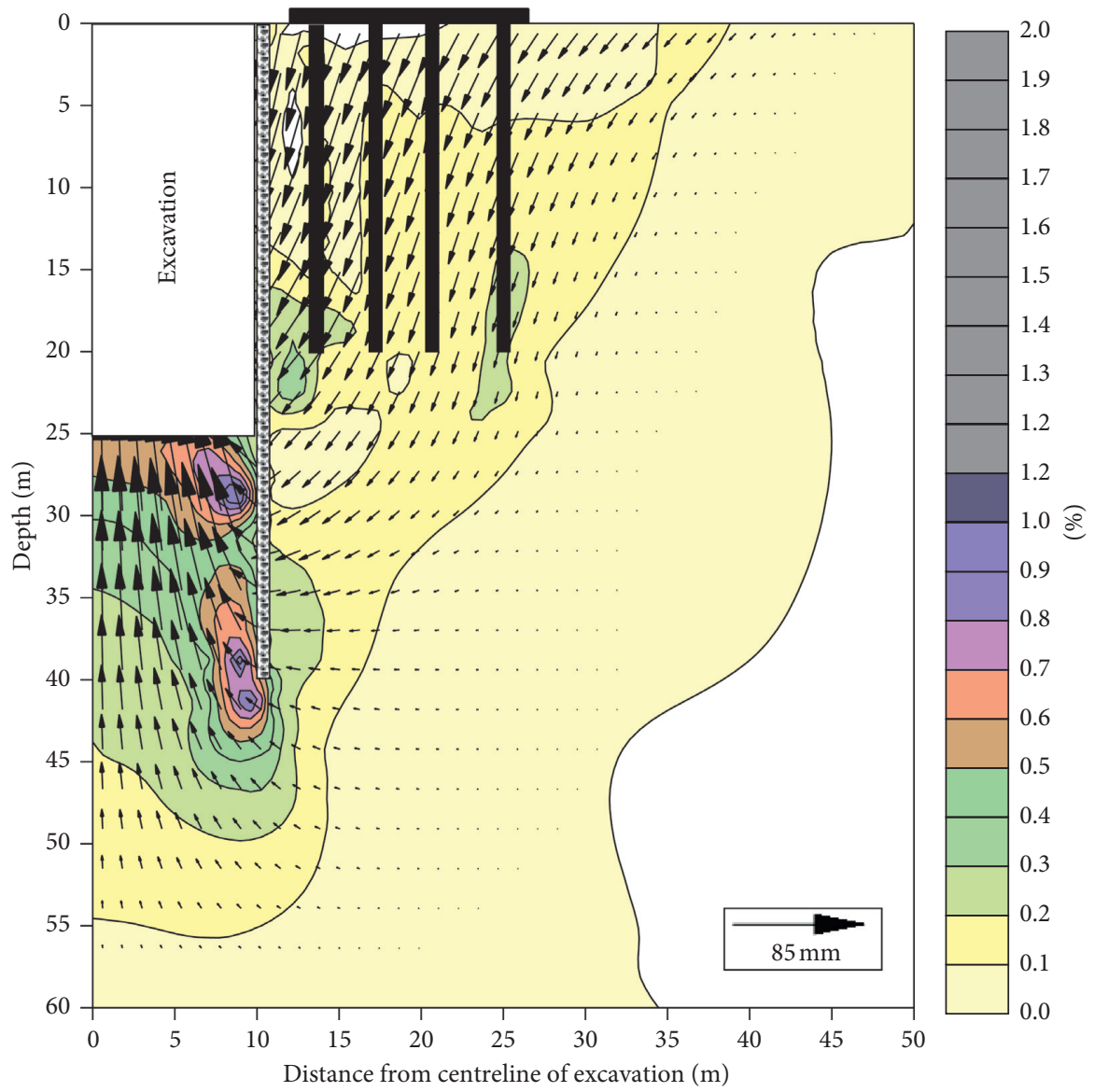

Figure 9: Computed soil displacement vectors and incremental deviatoric strain contours due to excavation. 
the other hand, the toe of the closest pile is located within the region where shear strain is developed. As illustrated, the presence of the pile further increases the shear strain of soil near the pile toe, as more end bearing has to be mobilized to support vertical load transferred from the pile shaft to the pile toe after excavation.

\subsection{Changes in Load Taken by the Raft during Excavation.} After construction of the building resting on a piled raft system, some of the building load is sustained by the raft and remaining load is transferred to the piles. However, the load taken by the raft can be altered when excavation is performed close to piles. Figure 10 represents the change in load sharing by the raft at different depths of excavations. It can be seen that before excavation (after application of working load), about $5.9 \%$ of the building load (i.e., 57.6 MN) was carried by the raft and the rest of the load was transferred to sixteen piles. It can be observed that the load taken by the raft kept decreasing during excavation. As the excavation depth increases, rate of reduction of the load is the highest. This indicates that the building load was transferred to piles on completion of excavation. This can be attributed to the raft settlement and induced ground settlement. On completion of the excavation, the load resisted by the raft reduced to $4.85 \%$ of the total load.

3.6. Changes in Axial Load Distribution along Piles. As discussed in the previous section, the load taken by the raft altered substantially due to the excavation. It suggests that changes in axial load distribution along 16 piles can be induced. Since arrangement of the 16 piles in the piled raft system is in a square pattern (i.e., $4 \times 4$ piles), the piles at critical positions are selected for discussion in this section. The piles are designated as $\mathrm{P} 1, \mathrm{P} 2, \mathrm{P} 3$, and P4 (see the inset in Figure 11). Figure 11(a) compares axial load distribution along the lengths of piles P1 and P4. For comparison, load distribution along the length of each pile before the excavation is included in each figure. It can be observed from the figure that the load taken by the piles positioned at the corner of the raft (i.e., P1 and P4) is same, whereas piles in the middle of the raft shared equal load before excavation. Before excavation, the load taken by the piles $\mathrm{P} 1$ and $\mathrm{P} 4$ is $3517 \mathrm{kN}$. Both piles resisted the load by shaft resistance (36\% of the load), and the remainder resisted by end bearing. On completion of the excavation, the axial load along the entire pile length of piles P1 and P4 increased. This indicates that shaft resistance decreased along the length of both the piles. This observation can be attributed to excavation-induced shear stain due to stress release at the midportion of the pile (discussed in Section 3.4). To support the load, shaft resistance was mobilized at the lower portion of the pile. Figure 11(b) compares axial load distribution along the length of piles P2 and P3. For comparison, load distribution along the length of each pile before the excavation is included in each figure. It can be seen from the figure that before excavation, the load transferred to each of the piles P2 and $\mathrm{P} 3$ was $3160 \mathrm{kN}$. The piles resisted the load by mobilizing shaft resistance ( $40 \%$ of load) along the lower portion the

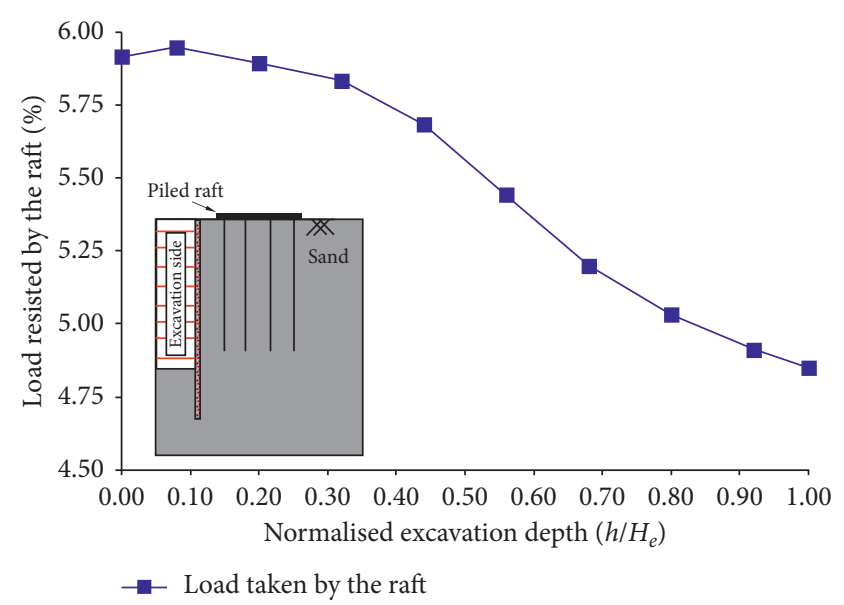

Figure 10: Changes in load resisted by the raft during excavation.

pile length, and remainder $60 \%$ of the load was resisted by end bearing. It can be seen from the figure that similar to the changes in axial load distribution along the pile length of P1 and $\mathrm{P} 4$, the axial load along the entire pile length of $\mathrm{P} 2$ and P4 increased on completion of the excavation. This load redistribution is ascribed to excavation-induced stress release and load transfer from the raft to piles. The end bearing of both the piles P2 and P3 increased by 10\% to carry the transferred load from the raft.

\subsection{Structural Response of Pile (Induced Bending Moment and} Shear Forces along Piles). Before excavation, the piles are horizontally confined by the surrounding soil and are subjected to negligible shear forces and bending moments. However, when excavation is carried out near piles and induces stress release in the ground, the substantial shear forces and bending moment can be produced in the piles. Thus, the shear forces and bending moment induced along piles due to excavation are important parameters to be predicted. Figure 12 illustrates the induced shear forces along normalised depth of four selected piles (i.e., P1, P2, P3, and P4) on completion of excavation. A highly nonlinear shear force distribution was predicted along each pile in each case. Due to rigid connection between the piles and raft, the maximum shear force generated is at the head of the piles. However, the magnitude of the maximum shear force was dependent on the location of the piles in the raft. The piles at the corners of the raft (P1 and P4) and the middle of the raft (P2 and P3) are subjected to positive and negative shear forces, respectively. The maximum shear forces developed at pile heads P1, P2, P3, and $\mathrm{P} 4$ were $730 \mathrm{kN}, 600 \mathrm{kN}, 550 \mathrm{KN}$, and $250 \mathrm{kN}$, respectively. This is because of excavation-induced stress release and ground movement towards excavation.

Since the piles are mostly designed to carry vertical load, the bending moment induced in the piles is another important parameter to investigate due to adjacent excavation. Figure 13 shows the induced bending moments along the normalised depth of four selected piles (i.e., P1, P2, P3, and P4) on completion of excavation. It is clear evidence from the figures that the maximum bending moment is induced at 


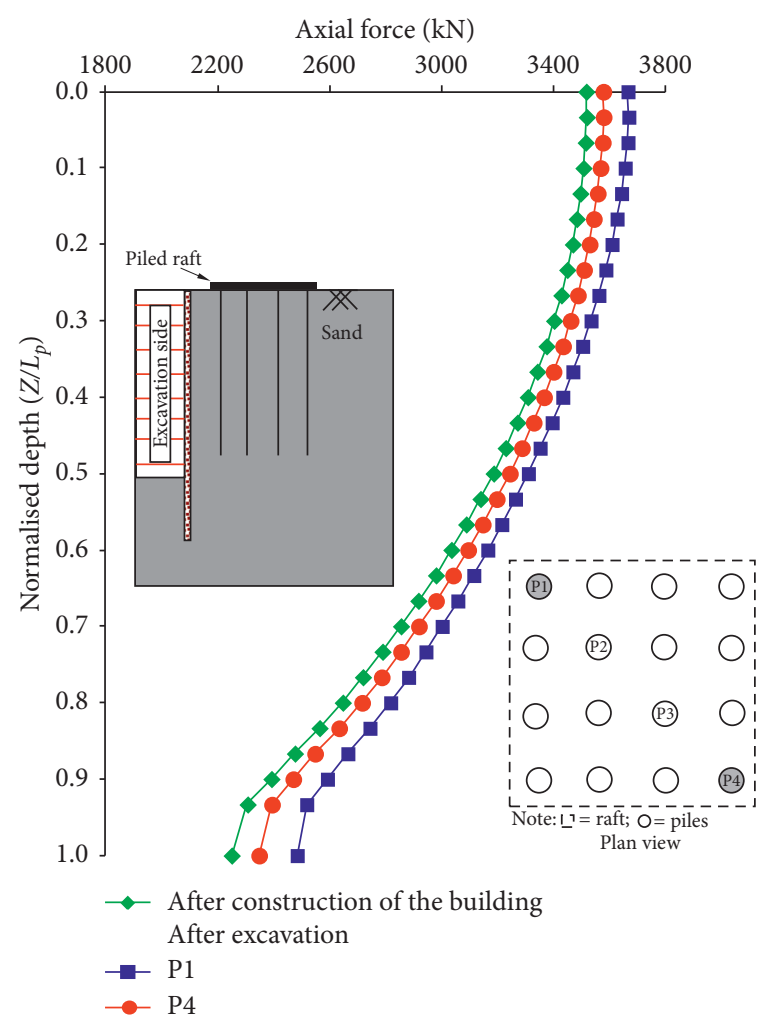

(a)

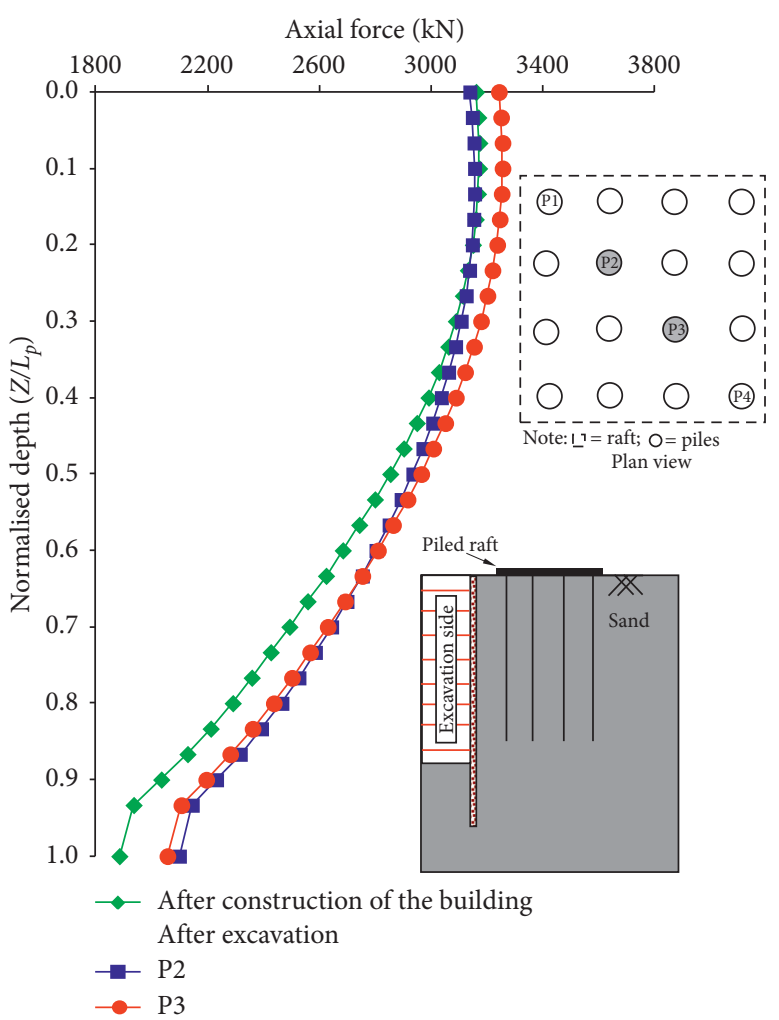

(b)

Figure 11: Axial load distribution before and after tunnelling in each case along the lengths of piles. (a) P1 and P4. (b) P2 and P3.

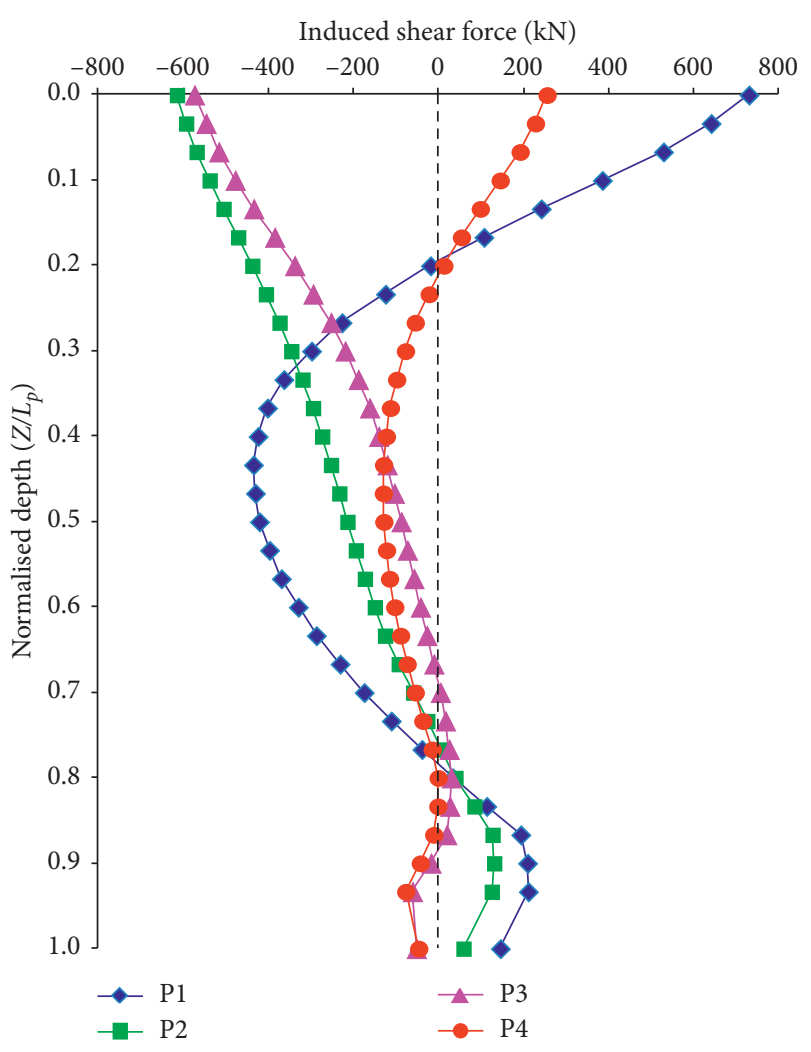

FIGURE 12: Induced shear force along four piles (i.e., P1, P2, P3, and P4).

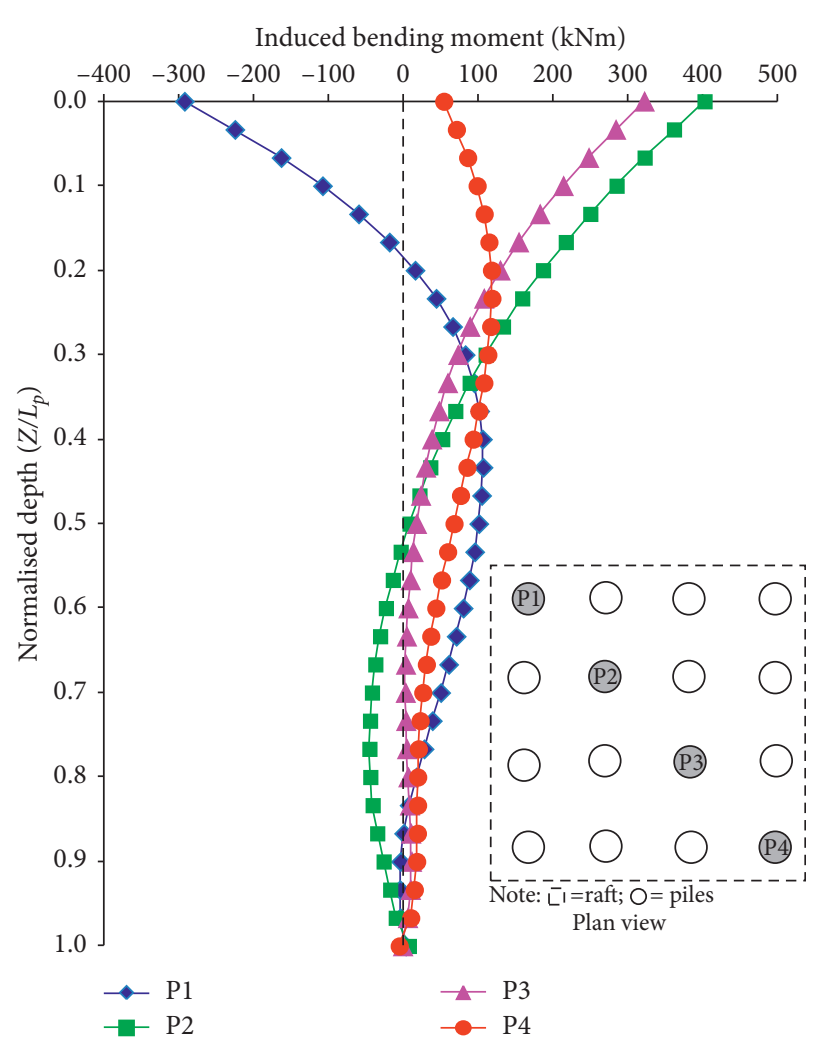

FIGURE 13: Induced bending moment along four piles (i.e., P1, P2, $\mathrm{P} 3$, and P4). 
the head of each pile. This is because the piles are rigidly connected to the raft. The maximum negative bending moment $(300 \mathrm{kNm})$ was predicted at the head of pile P1. To counterbalance the negative bending moment, positive bending moment was induced at the lower portion of the pile $\left(Z / L_{p}>0.2\right)$. The remaining piles (P2, P3, and $\left.\mathrm{P} 4\right)$ were subjected to positive bending moment at their heads. Since the pile toes were free to move, negligible bending moment was induced at the toes of each piles.

\section{Conclusions}

Based upon the analysis and results, the following specific conclusions are drawn:

(1) Owing to degradation of soil stiffness, bilinear increment in Sp was observed with increasing of excavation depth. $S_{p}$ increased linearly when excavation depth reached $h / H_{e}=0.68$; however, the rate of induced settlement further increased until final excavation depth $\left(h / H_{e}=1.00\right)$. With settlement due to working load (i.e., $4.8 d_{p} \%$ ), the total settlements of the building $\left(7.8 d_{p} \%\right)$ exceed the maximum allowable foundation settlement (i.e., $50 \mathrm{~mm}$ ) according to Skempton and Macdonald and O'Brien.

(2) After the completion of the first excavation stage (i.e., $h /$ $H_{e}=0.08$ ), negligible differential settlement was induced. However, as excavation depth increases, the differential settlement increases. This observation is attributed to excavation-induced stress release which is larger and smaller around the pile closest to and farthest from the excavation. The differential settlement in the raft of 3.6, 7.4, and $16.7 \mathrm{~mm}$ was induced on completion of excavation stages $h / H_{e}=0.56,0.80$, and 1.00 , respectively.

(3) The excavation resulted in differential settlement of the raft. This led to displace the 20 -storey building laterally towards the excavation which caused the building permanent interstorey drifts. The interstorey drift may induce distress in structural component of the building.

(4) The load taken by the raft (about $5.9 \%$ of the building loads, i.e., $57.6 \mathrm{MN}$ before excavation) can be altered when excavation is performed close to piles. On completion of the excavation, the load resisted by the raft reduced to $4.85 \%$ of the total load.

(5) Apart from induced settlement, differential settlement, lateral movement, and interstorey drift in the building due to excavation, the piles are also subjected to substantial shear forces and bending moment along pile lengths.

\section{Data Availability}

The data used to support the findings of this study are available from the corresponding author upon request.

\section{Conflicts of Interest}

The authors declare that they have no conflicts of interest.

\section{Acknowledgments}

The authors would like to acknowledge the financial support provided by the Quaid-e-Awam University of Engineering, Science \& Technology, Sindh, Pakistan.

\section{References}

[1] J. Shi, C. Ding, C. W. W. Ng, H. Lu, and L. Chen, "Effects of overconsolidation ratio on tunnel responses due to overlying basement excavation in clay," Tunnelling and Underground Space Technology, vol. 97, Article ID 103247, 2020.

[2] J. Shi, G. Liu, P. Huang, and C. W. W. Ng, "Interaction between a large-scale triangular excavation and adjacent structures in Shanghai soft clay," Tunnelling and Underground Space Technology, vol. 50, pp. 282-295, 2015.

[3] M. Son and E. J. Cording, "Evaluation of building stiffness for building response analysis to excavation-induced ground movements," Journal of Geotechnical and Geoenvironmental Engineering, vol. 133, no. 8, pp. 995-1002, 2007.

[4] M. Rocha, "The possibility of solving soil mechanics problems by use of models," in Proceedings of 4th International Conference on Soil Mechanics and Foundation Engineering, vol. 1, pp. 183-188, London, UK, August 1957.

[5] P. Moncarz and H. Krawinkler, "Theory and application of experimental model analysis in earthquake engineering," John A. Blume Earthquake Engineering Center Stanford University, Stanford, CA, USA, Rpt. No. 50, 1981.

[6] M. E. Sawwaf and A. K. Nazir, "The effect of deep excavation induced lateral soil movements on the behavior of strip footing supported on reinforced sand," Journal of Advanced Research, vol. 3, no. 4, pp. 337-344, 2012.

[7] Y. Fang, C. Xu, G. Cui, and B. Kenneally, "Scale model test of highway tunnel construction underlying mined-out thin coal seam," Tunnelling and Underground Space Technology, vol. 56, pp. 105-116, 2016.

[8] X. Yang, P. H. S. W. Kulatilake, H. Jing, and S. Yang, "Numerical simulation of a jointed rock block mechanical behavior adjacent to an underground excavation and comparison with physical model test results," Tunnelling and Underground Space Technology, vol. 50, pp. 129-142, 2015.

[9] H. M. Shahin, E. Sung, T. Nakai et al., "2D model tests and numerical simulation in shallow tunneling considering existing building load," Underground Construction and Ground Movement, vol. 155, pp. 304-311, 2006.

[10] H. M. Shahin, T. Nakai, M. Hinokio, T. Kurimoto, and T. Sada, "Influence of surface loads and construction sequence on ground response due to tunnelling," Soils and Foundations, vol. 44, no. 2, pp. 71-84, 2004.

[11] W.-C. Cheng, J. C. Ni, A. Arulrajah, and H.-W. Huang, "A simple approach for characterising tunnel bore conditions based upon pipe-jacking data," Tunnelling and Underground Space Technology, vol. 71, pp. 494-504, 2018.

[12] A. Kusui, E. Villaescusa, and T. Funatsu, "Mechanical behaviour of scaled-down unsupported tunnel walls in hard rock under high stress," Tunnelling and Underground Space Technology, vol. 60, pp. 30-40, 2016.

[13] H. Xu, T. Li, L. Xia, J. X. Zhao, and D. Wang, "Shaking table tests on seismic measures of a model mountain tunnel," 
Tunnelling and Underground Space Technology, vol. 60, pp. 197-209, 2016.

[14] D. S. Liyanapathirana and R. Nishanthan, "Influence of deep excavation induced ground movements on adjacent piles," Tunnelling and Underground Space Technology, vol. 52, pp. 168-181, 2016.

[15] R. Zhang, J. Zheng, H. Pu, and L. Zhang, "Analysis of excavation-induced responses of loaded pile foundations considering unloading effect," Tunnelling and Underground Space Technology, vol. 26, no. 2, pp. 320-335, 2011.

[16] K. Yashiro, K. Shimamoto, and Y. Kojima, "Proposal of guideline for judgment of adjacent level on adjacent construction of existing tunnels," Quarterly Report of RTRI, vol. 49, no. 2, pp. 79-84, 2008.

[17] S. J. Boone, J. Westland, and R. Nusink, "Comparative evaluation of building responses to an adjacent braced excavation," Canadian Geotechnical Journal, vol. 36, no. 2, pp. 210-223, 1999.

[18] E. C. L. Hsiao, C. H. Juang, G. T. C. Kung, and M. Schuster, "Reliability analysis and updating of excavation-induced ground settlement for building serviceability excavation," in Proceedings of Probabilistic Applications in Geotechnical Engineering, vol. 170, pp. 1-10, Denver, CO, USA, February 2007.

[19] E. C. Hsiao, M. Schuster, C. H. Juang, and G. T. Kung, "Reliability analysis and updating of excavation-induced ground settlement for building serviceability assessment," Journal of Geotechnical and Geoenvironmental Engineering, vol. 134, no. 10, pp. 1448-1458, 2008.

[20] M. Long, "Database for retaining wall and ground movements due to deep excavations," Journal of Geotechnical and Geoenvironmental Engineering, vol. 127, no. 3, pp. 203-224, 2001.

[21] J. Shi, J. Wei, C. W. W. Ng, and H. Lu, "Stress transfer mechanisms and settlement of a floating pile due to adjacent multi-propped deep excavation in dry sand," Computers and Geotechnics, vol. 116, Article ID 103216, 2019.

[22] J. Shi, Z. Fu, and W. Guo, "Investigation of geometric effects on three-dimensional tunnel deformation mechanisms due to basement excavation," Computers and Geotechnics, vol. 106, pp. 108-116, 2019.

[23] S. Yu and Y. Geng, "Influence analysis of underground excavation on the adjacent buildings and surrounding soil based on scale model test," Advances in Civil Engineering, vol. 2019, p. 15, Article ID 6527175, 2019.

[24] W.-C. Cheng, L. Wang, Z.-F. Xue, J. C. Ni, M. Rahman, and A. Arulrajah, "Lubrication performance of pipejacking in alluvial deposits," Tunnelling and Underground Space Technology, vol. 91, p. 102991, 2019.

[25] P. B. Shing and T. Tanabe, Modeling of Inelastic Behavior of RC Structures under Seismic Loads, ASCE Publications, Reston, VI, USA, 2001.

[26] M. A. Soomro, D. A. Mangnejo, R. Bhanbhro, N. A. Memon, and M. A. Memon, "3D finite element analysis of pile responses to adjacent excavation in soft clay: effects of different excavation depths systems relative to a floating pile," Tunnelling and Underground Space Technology, vol. 86, pp. 138$155,2019$.

[27] Standards Australia, Structural Design Actions; Part 1 Permanent, Imposed and other Actions, Standards Australia, Sydney Australia, AS1170.1, 2002.

[28] A. W. Skempton and D. H. Macdonald, "The allowable settlements of buildings," Proceedings of the Institution of Civil Engineers, vol. 5, no. 6, pp. 727-768, 1956.
[29] A. S. O’Brien, “Chapter 52 foundation types and conceptual design principles," ICE Manual of Geotechnical Engineering, vol. II, pp. 733-764, 2012.

[30] H. Rasouli and B. Fatahi, "A novel cushioned piled raft foundation to protect buildings subjected to normal fault rupture," Computers and Geotechnics, vol. 106, pp. 228-248, 2019.

[31] Computers and Structures Inc, SAP2000 14 [Computer Software], Computers and Structures Inc., Berkeley, CA, USA.

[32] Standards Australia, Concrete Structures, Standards Australia, Sydney, Australia, AS3600, 2009.

[33] Standards Australia, Structural Design Actions; Part 4: Earthquake Actions in Australia, Standards Australia, Sydney, Australia, AS1170.4, 2007.

[34] J. H. Atkinson, D. Richardson, and S. E. Stallebrass, "Effect of recent stress history on the stiffness of overconsolidated soil," Géotechnique, vol. 40, no. 4, pp. 531-540, 1990.

[35] M. A. Soomro, M. Kumar, H. Xiong, D. A. Mangnejo, and N. Mangi, "Investigation of effects of different construction sequences on settlement and load transfer mechanism of single pile due to twin stacked tunnelling," Tunnelling and Underground Space Technology, vol. 96, Article ID 103171, 2020.

[36] M. A. Soomro, A. Saand, N. Mangi, D. A. Mangnejo, H. Karira, and K. Liu, "Numerical modelling of effects of different multipropped excavation depths on adjacent single piles: comparison between floating and end-bearing pile responses," European Journal of Environmental and Civil Engineering, 2020.

[37] W.-C. Cheng, J. C. Ni, H.-W. Huang, and j. S. Shen, “The use of tunnelling parameters and spoil characteristics to assess soil types: a case study from alluvial deposits at a pipejacking project site," Bulletin of Engineering Geology and the Environment, vol. 78, no. 4, pp. 2933-2942, 2019.

[38] W.-C. Cheng, G. Li, N. Liu, J. Xu, and S. Horpibulsuk, "Recent massive incidents for subway construction in soft alluvial deposits of Taiwan: a review," Tunnelling and Underground Space Technology, vol. 96, p. 103178, 2020.

[39] A. Niemunis and I. Herle, "Hypoplastic model for cohesionless soils with elastic strain range," Mechanics of CohesiveFrictional Materials, vol. 2, no. 4, pp. 279-299, 1997.

[40] I. Herle and G. Gudehus, "Determination of parameters of a hypoplastic constitutive model from properties of grain assemblies," Mechanics of Cohesive-Frictional Materials, vol. 4, no. 5, pp. 461-486, 1999.

[41] C. W. W. Ng, Y. Hong, and M. A. Soomro, "Effects of piggyback twin tunnelling on a pile group: 3D centrifuge tests and numerical modelling," Géotechnique, vol. 65, no. 1, pp. 38-51, 2015.

[42] J. Jáky, "The coefficient of earth pressure at rest," Journal of the Society Hungarian Society of Engineers and Architects, vol. 78, no. 22, pp. 355-358, 1944, in Hungarian.

[43] K. Hibbitt, Sorensen, Abaqus User's Manual, Version 6.14-2, Hibbitt, Karlsson \& Sorensen Inc, Providence, RI, USA, 2014. 